\title{
PENGARUH MODEL INQUIRY LEARNING DAN DIRECT INSTRUCTION \\ DALAM PENDIDIKAN JASMANI TERHADAP KEMAMPUAN BERPIKIR KRITIS SISWA SEKOLAH MENENGAH PERTAMA
}

\author{
Eko Prasetyo \\ epras10@gmail.com \\ STKIP Subang
}

\begin{abstract}
This study aims to determine the effect between instructional model Inquiry Learning and Direct Instruction to critical thinking skills of Junior High School children in accordance with gender differences between men and women. The method used in this research is to use the experimental method using a quantitative approach with the type of case study. In this study, the measurement tool is a questionnaire that the author quotes from the questionnaire Bambang Abduljabar. The results of this study are: Inquiry learning model in learning pemas can improve students' critical thinking skills without feared will be influenced by sex differences in students. The more student-centered learning of lead will contribute positively to the students' cognitive development, even giving the student a pleasurable learning experience.
\end{abstract}

Keywords: Inquiry Learning, Direct Instruction, Critical Thinking

\begin{abstract}
ABSTRAK
Penelitian ini bertujuan untuk mengetahui pengaruh antara model pembelajaran Inquiry Learning dan Direct Instruction terhadap kemampuan berpikir kritis anak Sekolah Menengah Pertama sesuai dengan perbedaan gender antara laki-laki dan perempuan. Metode yang digunakan dalam penelitian ini adalah dengan menggunakan metode eksperimen dengan menggunakan pendekatan kuantitatif dengan jenis studi kasus. Dalam penelitian ini, alat pengukurannya berupa angket yang penulis kutip dari angket Bambang Abduljabar. Adapun hasil dari penelitian ini yaitu : Model pembelajaran inkuiri dalam pembelajaran penjas dapat meningkatkan kemampuan berpikir kritis siswa tanpa dikhawatirkan akan dipengaruhi oleh perbedaan jenis kelamin pada siswa. Pembelajaran penjas yang lebih berpusat pada siswa akan memberikan kontribusi positif terhadap perkembangan kognitif siswa, bahkan memberikan siswa pengalaman belajar yang menyenangkan.
\end{abstract}

Kata Kunci: Inquiry Learning, Direct Instruction, Berpikir Kritis 


\section{A. Pendahuluan}

Berpikir kritis merupakan salah satu aspek penting yang harus dimiliki oleh setiap individu pada Abad 21. Individu dituntut mampu berpikir secara logis dan saintifik sehingga terhindar dari pemikiran berupa mitos dan budaya ikut- ikutan yang belum tentu menguntungkan bagi diri individu maupun bagi masyarakat. Sikap stereotip masyarakat pun masih sangat kental dalam pemilahan aktivitas fisik. Penyelenggaraan pendidikan formal salah satunya sekolah merupakan salah satu upaya agar peserta didik memiliki pola pikir dan cara pandang kritis terhadap sebuah isu. Pola pikir tentunya akan sangat berguna bagi individu untuk mampu menyelesaikan masalah.

Tentunya tidaklah mudah menghasilkan seorang individu yang terdidik dan memiliki kemampuan berpikir kritis. Peserta didik perlu mengalami pembelajaran yang mendukung terjadinya proses belajar yang mampu meningkatkan kemampuan berpikir kritis peserta didik. Namun, kondisi sekolah selama ini seperti yang dinyatakan oleh Muchtar Buchori (Cholisin, 2007) hanyalah memberi kemampuan untuk menghafal dan bukan untuk berpikir. Hasilnya pendidikan kita tidak mempunyai makna. Oleh karenanya sekolah harus memenuhi tiga aspek yaitu pengetahuan, skill, dan membentuk karakter. Aspek pengetahuan yang dikembangkan seharusnya dapat menopang kebutuhan skill yang terus berubah. Pentingnya materi yang dikuasai anak didik harus bisa mengikuti perkembangan kehidupan, kapan dan dimanapun.

Kondisi ini secara kasat mata ditunjukkan oleh hasil survey LPMP Jawa Barat (2008) bahwa kemampuan siswa SMP kelas dua di Jawa Barat dalam menyelesaikan soal-soal gerak sangat lemah, namun relatif baik dalam menyelesaikan tugas gerakan yang dicontohkan oleh gurunya. Hal ini membuktikan bahwa terhadap masalah penjas yang menuntut kemampuan berpikir tingkat tinggi, siswa SMP kelas dua Indonesia jauh di bawah rata-rata. Melihat keadaan seperti ini, upaya untuk meningkatkan 
kualitas pembelajaran terutama dalam pengembangan kemampuan berpikir tingkat tinggi siswa menjadi penting dan mendesak.

Kelemahan pembelajaran pendidikan jasmani yang terjadi seperti itu sebenarnya tidak bisa dilepaskan dari pemahaman terhadap eksistensi pendidikan jasmani sebagai salah satu komponen penting dalam tatanan kurikulum. Cukup banyak pakar termasuk para pengambil keputusan yang menyatakan bahwa pendidikan jasmani itu penting, namun ketika dihadapkan pada tataran praktis mendapat kesulitan yang begitu kompleks. Apa yang terjadi di lapangan ternyata tidak sesuai dengan yang dikonsepsikan, seperti alokasi waktu belajar pendidikan jasmani yang terbatas yaitu hanya dua jam per minggu dan kualifikasi tenaga pengajar yang tidak sesuai.

Penelitian yang dilakukan oleh Stephani (2014, hlm. 100) yang melakukan meneliti pengaruh model pembelajaran inkuiri terhadap kemampuan berpikir kritis dan keterampilan bermain bola basket yang disesuaikan dengan educational setting yang mana pembelajaran bola besar pada kurikulum pendidikan jasmani hanya diberikan waktu empat kali pertemuan setiap semester, mengungkapkan fakta bahwa tidak terdapat peningkatan yang signifikan antara skor pre-test dan post-test kemampuan berpikir kritis pada kelompok yang menggunakan model pembelajaran inkuiri. Stephani (2014, hlm 101) mengungkapkan rekomendasi penelitian selanjutnya bahwa berpikir kritis merupakan aspek psikologis dan memerlukan waktu yang relatif lama untuk mengalami peningkatan, sehingga perlu adanya penelitian yang lebih lama untuk meningkatkan kemampuan berpikir kritis serta metodologi penelitian yang melibatkan variabel moderator seperti Motivasi, IQ, gaya belajar, jenis kelamin, gaya belajar dsb.

Peneliti berpandangan bahwa perlu adanya penelitian lebih lanjut terkait pengaruh model pembelajaran inkuiri terhadap berpikir kritis yang melibatkan variabel moderator jenis kelamin pada materi pembelajaran bola 
basket, karena budaya stereotip jenis kelamin pada bola basket masih sangat kental dan disinyalir menjadi salah satu faktor yang menghambat partisipasi siswa dalam pembelajaran penjas, sehingga pengetahuan dan pengalaman belajar yang diharapkan mampu memberikan pengalaman bermakna tidak dapat tercapai.

\section{B. Metode Penelitian}

Berdasarkan variable dan tujuan penelitian, metode yang digunakan dalam penelitian ini adalah dengan menggunakan metode eksperimen dengan menggunakan pendekatan kuantitatif, hal ini sesuai dengan yang dikemukakan Riduwan (2011, hlm. 50) "Eksperimen adalah suatu penelitian yang berusaha mencari

\begin{tabular}{llllll}
\hline Treatment & $\mathrm{R}$ & $O$ & $X$ & $Y_{l}$ & $O$ \\
\cline { 2 - 6 } $\begin{array}{l}\text { Control } \\
\text { Treatment }\end{array}$ & $\mathrm{R}$ & $O$ & $C$ & $Y_{1}$ & $O$ \\
\cline { 2 - 6 } Control & $\mathrm{R}$ & $O$ & $X$ & $Y_{2}$ & $O$ \\
\cline { 2 - 6 } & $\mathrm{R}$ & $O$ & $C$ & $Y_{2}$ & $O$
\end{tabular}

menggunakan perlakuan (treatment) dengan memberikan metode pembelajaran inquiry terhadap kelompok eksperimen dan kelompok kontrol dengan menggunakan

metode pembelajaran langsung (Direct Instructon). Pada penelitian ini mencari pengaruh metode pembelajaran yang digunakan terhadap berpikir kritis siswa.

Sesuai dengan tujuan penelitian yang hendak dicapai, penelitian ini menggunakan desain factorial, seperti yang dijelaskan Fraenkel (1993, hlm. 256): ..., it is possible using a factorial design to assess not only separate effect of each independent variable but also joint effect. In other words, the researcher is able to see how one of the variable might moderate the other (hence the reason for calling these variable moderator variables).

Berikut desain penelitian faktorial yang dikemukan oleh Fraenkel (1993, hlm. 255):

\section{Gambar 1 Desain Faktorial}

Fraenkel (2011, hlm. 277) mengemukakan bahwa "Desain factorial ini merupakan modifikasi 
dari desain pretest posttest control group design. Pada desain ini melibatkan satu kelompok perlakuan dan satu kelompok control, dan sebuah variabel moderator yang memiliki dua tingkatan ( $\mathrm{Y} 1$ dan $\mathrm{Y} 2)$ ". Karena masing-masing variabel, atau faktor, memiliki dua level, desain diatas disebut factorial $2 \times 2$. Berikut alternatif ilustrasi desain faktorial disajikan pada Tabel 1 di bawah ini:

Tabel 1 Desain Faktorial $2 \times 2$

\begin{tabular}{|c|c|c|}
\hline $\begin{array}{c}\text { Metode } \\
\text { Pembelajaran }\end{array}$ & $\begin{array}{c}\text { Metode Pembelajaran } \\
\text { Inquiry } \\
\mathrm{X}_{1}\end{array}$ & $\begin{array}{c}\text { Metode Pembelajaran } \\
\text { Langsung } \\
\text { Siswa }\end{array}$ \\
\hline Laki-laki $\mathrm{Y}_{1}$ & $\mathrm{X}_{1} \mathrm{Y}_{1}$ & $\mathrm{X}_{2} \mathrm{Y}_{2}$ \\
\hline Perempuan $\mathrm{Y}_{2}$ & $\mathrm{X}_{1} \mathrm{Y}_{2}$ & $\mathrm{X}_{2} \mathrm{Y}_{2}$ \\
\hline
\end{tabular}

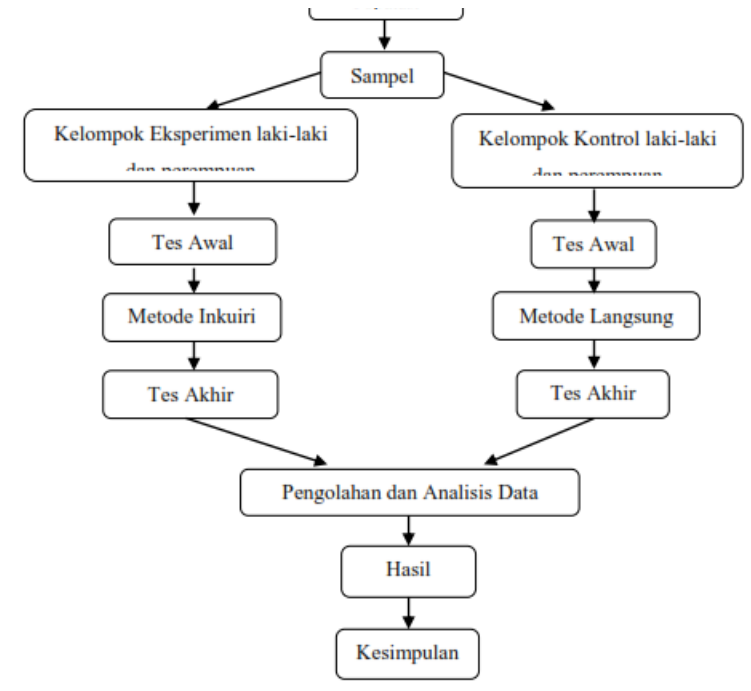

inquiry

$\mu$ A1B2 $=$ Kelompok siswi Perempuan yang diajar dengan menggunakan metode pembelajaran inquiry.

$\mu$ A2B1 $=$ Kelompok siswa laki-laki yang diajar dengan menggunakan metode pembelajaran langsung.

$\mu$ A2B2 $=$ Kelompok siswi perempuan yang diajar dengan menggunakan metode pembelajaran langsung.

Agar lebih jelas jalannya penelitian yang dilakukan, maka berikut ini adalah bagan prosedur penelitian yang dilakukan, yaitu :

Gambar 2 Prosedur Penelitian

Penelitian ini dilaksanakan selama 4 minggu dari bulan Maret hingga April 2015 dengan 
frekuensi 2 kali pertemuan setiap minggu. Pengambilan data pretest, akan dilakukan pada pertemuan pertama sebelum perlakuan diberikan. Data post-test diambil pada pertemuan kedelapan setelah perlakuan diberikan.

Materi pembelajaran bola basket dipilih karena saat penelitian akan dilakukan materi yang seharusnya diberikan yaitu materi permainan bola besar yaitu bola basket. Berikut program pembelajaran materi basket ball like games :

Tabel 1. Bentuk permainan

\begin{tabular}{|c|c|}
\hline Pertemuan & Materi \\
\hline 1 & $\begin{array}{c}\text { (Pengambilan data } \\
\text { pre-test) }\end{array}$ \\
\hline 2 & Ten ball \\
\hline 3 & End zone \\
\hline 4 & Circle ball \\
\hline 5 & Three mat ball \\
\hline 6 & Window ball \\
\hline 7 & $\begin{array}{c}\text { Wall ball } \\
\text { target }\end{array}$ \\
\hline 8 & $\begin{array}{c}\text { Game Situation } \\
\text { (Pengambilan data } \\
\text { post-test) }\end{array}$ \\
\hline 9
\end{tabular}

Populasi yang ditentukan dalam penelitian ini adalah siswa kelas VIII di SMP 45 Bandung sebanyak 300 siswa yang terdiri dari 10 kelas dengan rata-rata setiap kelas terdiri dari 30 orang.

Teknik pengambilan sampel dalam penelitian ini menggunakan

\begin{tabular}{|c|c|c|c|}
\hline $\begin{array}{c}\text { Metode } \\
\text { Pembelajaran }\end{array}$ & $\begin{array}{c}\text { Metode } \\
\text { Pembelajaran } \\
\text { Inquiry } \\
\text { Jenis kelamin } \\
\text { Siswa }\end{array}$ & $\begin{array}{c}\text { Metode } \\
\text { Pembelajaran } \\
\text { Langsung } \\
\text { A2 }\end{array}$ & Total \\
\hline Laki-laki B1 & 15 & 15 & 30 \\
\hline Perempuan B2 & 15 & 15 & 30 \\
\hline Total & 30 & 30 & 60 \\
\hline
\end{tabular}

jadi peneliti mengambil sebanyak dua kelas sebagai sampel penelitian sesuai dengan kebutuhan peneliti dalam penelitian ini.

Keterangan :

A1 = Metode pembelajaran inquiry
A2 = Metode pembelajaran langsung
B1 = Jenis kelamin laki-laki
B2 = Jenis kelamin perempuan

$\mu$ A1B1 = Kelompok siswa laki-laki yang diajar dengan menggunakan metode pembelajaran inquiry 
Didaktik : Jurnal Pendidikan Guru Sekolah Dasar, ISSN : 24775673

Sekolah Tinggi Keguruan dan IImu Pendidikan Subang Volume III Nomor 1, Desember 2017

HA1B2
Perempuan yang diajar
dengan
metode
inquiry.

$\mu \mathrm{A} 2 \mathrm{~B} 1=$ Kelompok siswa laki-laki yang diajar dengan menggunakan metode pembelajaran langsung.

$\mu \quad$ A2B2 $=$ Kelompok siswi perempuan yang diajar dengan menggunakan metode pembelajaran langsung.

\section{Hasil Penelitian}

Berdasarakan hasil pengolahan dan analisis data yang telah dilakukan, dapat ditarik kesimpulan sebagai berikut:

\section{Terdapat}

peningkatan

kemampu-an berpikir kritis pada siswa laki-laki yang belajar melalui model Inquiry Learning.

2. Terdapat peningkatan peningka-tan kemampuan berpikir kritis pada siswa perempuan yang belajar melalui model Inquiry Learning.

3. Tidak terdapat peningkatan kemampuan berpikir kritis pada siswa laki-laki yang belajar melalui model Direct Instruction.
4. Terdapat

peningkatan kemampuan berpikir kritis pada siswa perempuan yang belajar melalui model Direct Instruction.

5. Tidak terdapat interaksi antara model pembelajaran dengan jenis kelamin terhadap kemampuan berpikir kritis.

\section{Kesimpulan}

Berdasarkan hasil penelitian ini, peneliti membuat kesimpulan sebagai berikut :

1. Model pembelajaran inkuiri dalam pembelajaran penjas dapat meningkatkan kemampuan berpikir kritis siswa tanpa dikhawatirkan akan dipengaruhi oleh perbedaan jenis kelamin pada siswa.

2. Pembelajaran penjas yang lebih berpusat pada siswa akan memberikan kontribusi positif terhadap perkembangan kognitif siswa, bahkan memberikan siswa pengalaman belajar yang menyenangkan.

DAFTAR PUSTAKA 
Abduljabar, Bambang. (2009).

Pengaruh

Program

Pembelajaran Kognitif Dalam

Pengajaran Olahraga Tenis

dan Program Pembelajaran

Konvensional

Dalam

Pengajaran Olahraga Futsal

untuk

Pengembangan

Keterampilan Berpikir Kritis

dan Atensi Kinestetik pada

Siswa Sekolah Menengah

Pertama. Bandung. Desertasi SPS UPI.

Arikunto, S. (2010). Prosedur

Penelitian Suatu Pendekatan

Praktek. Jakarta: Rineka Cipta.

Desmita (2012). Psikologi

Perkembangan Peserta Didik.

Bandung: PT Remaja

Rosdakarya.

Faiz, Fahrudin (2012). Thinking

Skill: Pengantar menuju berpikir kritis.

Yogyakarta: Suka-Press UIN

Sunan Kalijaga

Filsaime. Dennis K. (2007) Alih

Bahasa, Sunarni. (2008).

Menguak Rahasia Berpikir

Kritis dan Kreatif. Jakarta:

Prestasi Pustaka raya.
Fisher, Alec (2009). Berpikir Kritis: sebuah pengantar. Penerbit Erlangga

Juliantine, Tite. (2010). Model Pembelajaran Inkuiri Dalam Pendidkan Jasmani Untuk Mengembangkan Kreativitas Siswa Sekolah Dasar. Disertasi Doktor pada Program Studi Pendidikan Olahraga UPI Bandung: tidak diterbitkan.

McBride, dkk. (1990). Teaching Critical Thinking Skills in the Psycomotor

Domain. The Clearing House :Vol. 63 (197-201).

McMillan, J H \& Schumacher, S. (2001). Research in Education a Conceptual Introduction Fifth Edition. New York : Longman.

Metzler, Michael W., (2000). Intructional Models for Physical Education. Massachusetts: Allyn and Bacon.

Mulyasa. (2007). Kurikulum Tingkat Satuan Pendidikan. Bandung: PT. Remaja Rosdakarya.

Nurlan, Kusmaedi dan Husdarta (2002). Pertumbuhan dan Perkembangan Peserta Didik. Bandung : FPOK UPI 
Pendidikan Nasional. (2003).

Undang-Undang

Republik

Indonesia Nomor 20 tahun 2003 tentang sistem pendidikan nasional. Jakarta: Diknas.

Ormrod, J E. (2008). Psikologi Pendidikan (Edisi KeenamJilid 1). Bandung: Erlangga.

Purnomo, Bambang. (2012). Hakikat Pendidikan Jasmani dan Kesehatan. [Online].

Tersedia:

http://www.scribd.com/bamzzpurnomo

9396/d/38204408Hakikat-

Pendidikan-Jasmani-Dan-

Kesehatan.[19 Agustus, 2012].

Rosdiani, Dini (2012). Model Pembelajaran Langsung dalam Pendidikan Jasmani dan Kesehatan. Bandung: CV ALFABETA

Rosdiani, Dini.

(2013).

Perencanaan Pembelajaran dalam Pendidikan Jasmani dan Kesehatan. Bandung: CV ALFABETA.

Sagala, Syaiful. (2012). Konsep dan Makna Pembelajaran. Bandung: CV ALFABETA.
Stephani, Mesa R. (2014).

Pengaruh Model Pembelajaran Inkuiri terhadap Kemampuan Berpikir Kritis dan Keterampilan Bermain Bola Basket. SPS UPI : Tidak diterbitkan.

Sugiyono. (2010). Metode Penelitian Pendidikan. Bandung: CV ALFABETA Trianto. (2007). ModelModel Pembelajaran Inovatif Berorientasi

Konstruktivistik. Konsep, Landasan Teoritis-Praktis dan Implementasinya. Jakarta: Prestasi Pustaka Publisher. Cetakan Pertama.

Trianto. (2009). Mendesain Model Pembelajaran Inovatif Progresif. Jakarta: KENCANA. Utami, Munandar. (1999) Mengembangkan Bakat dan Kreativitas Anak Sekolah. Jakarta: Gramedia Widiasarana Indonesia

Zamroni \& Mahfudz .2009. Panduan Teknis Pembelajaran Yang Mengembangkan Critical Thinking. Jakarta. Depdiknas [12 Agustus 2014] 